Review article

\title{
Exercise in bipolar patients: A systematic review
}

\author{
Matias Carvalho Aguiar Melo a,*, Elizabeth De Francesco Daher ${ }^{\mathrm{a}}$, \\ Saulo Giovanni Castor Albuquerque ${ }^{\mathrm{b}}$, Veralice Meireles Sales de Bruin ${ }^{\mathrm{a}}$ \\ a Department of Medical Sciences, Universidade Federal do Ceará, Brazil \\ ${ }^{\mathrm{b}}$ Hospital de Saúde Mental Professor Frota Pinto, Brazil
}

\section{A R T I C L E I N F O}

\section{Article history:}

Received 12 December 2015

Received in revised form

27 February 2016

Accepted 5 March 2016

Available online 15 March 2016

Keywords:

Physical activity

Sedentary lifestyle

Exercise

Bipolar disorder

Mania

\begin{abstract}
A B S T R A C T
Background: Sedentary lifestyle is frequent in psychiatric disorders, however the directions of this association and benefits of physical activity are unclear. This is a systematic review about exercise in patients with bipolar disorder.

Methods: We performed a systematic literature search of studies published in English (1995 Jan to 2016 Jan) in PubMed, and Cochrane Library combining the medical terms 'physical activity' or 'sedentary' or 'physical exercise' with 'bipolar disorder' or 'mania' or 'bipolar depression'.

Results: Thirty-one studies were selected and included 15,587 patients with bipolar disorder. Sedentary lifestyle varied from $40 \%$ to $64.9 \%$. Physical activity was associated with less depressive symptoms, better quality of life and increased functioning. Some evidence indicates a relationship between vigorous exercises and mania. Three prospective cohorts were reported; and no prospective randomized controlled trial was identified. Three studies focused on biomarkers in bipolar patients; and one reported the relationship between exercise and sleep in this group. Two assessed physical exercise in adolescents. Limitations: (1) Differences between studies preventing a unified analysis; (2) most studies were crosssectional; (3) motivation for exercising is a selection bias in most studies; (4) no intervention study assessing only physical exercise; (5) lack of studies comparing exercise across mood states.

Conclusion: Generally, exercise was associated with improved health measures including depressive symptoms, functioning and quality of life. Evidence was insufficient to establish a cause-effect relationship between mood and physical exercise. Future research including randomized trials is needed to clarify the role of physical activity in bipolar patients.
\end{abstract}

(c) 2016 Elsevier B.V. All rights reserved.

\section{Contents}

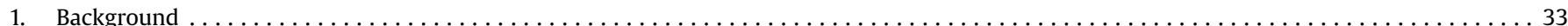

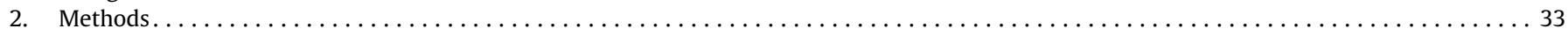

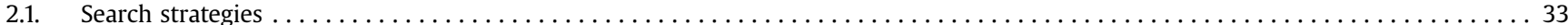

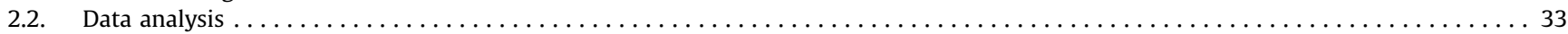

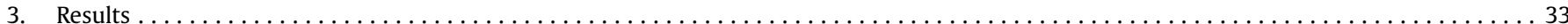

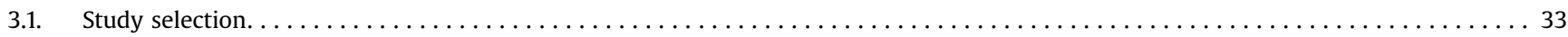

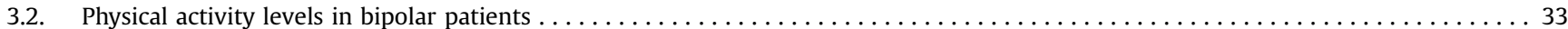

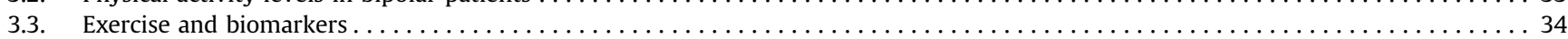

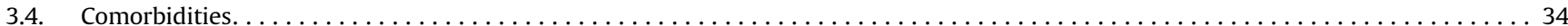

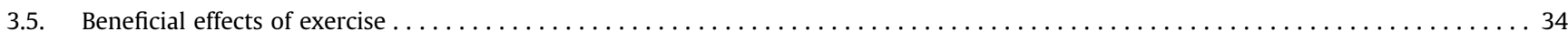

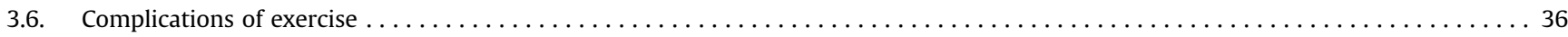

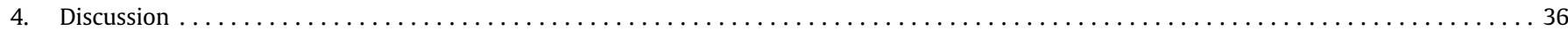

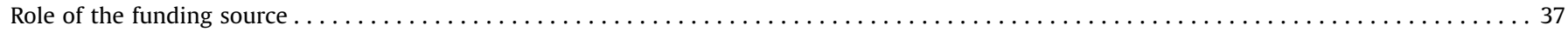

\footnotetext{
*Correspondence to: Department of Medical Sciences, Universidade Federal do Ceará, Av. Sargento Hermínio, 880 Quadra A. Bloco 5. Ap 201, Bairro: Monte Castelo, Fortaleza, CE CEP 60326-348, Brazil.

E-mail address: matcarv01@yahoo.com.br (M.C.A. Melo).
} 


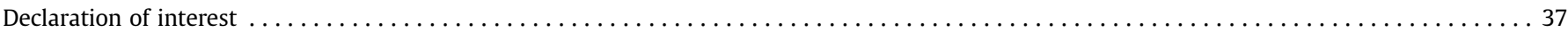

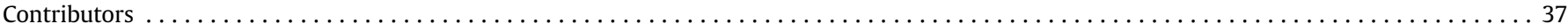

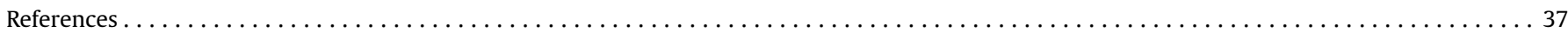

\section{Background}

Bipolar disorder is a chronic psychiatric condition associated with severe disability, high mortality rates and increased demand for health services (Anderson et al., 2012; Price and Marzani-Nissen, 2012) whose therapy generally is based on pharmacological and non-pharmacological interventions (Geddes and Miklowitz, 2013; Kendall et al., 2014; McCormick et al., 2015).

Physical activity is frequently indicated for the prevention and treatment of various mental disorders (Moylan et al., 2013; Ten Have et al., 2011). The anti-inflammatory properties of exercise and the high comorbidity with obesity, diabetes, hypertension and cardiovascular disease (increased by psychotropic action) support this recommendation (Morriss and Mohammed, 2005; Petersen and Pedersen, 2005).

Exercise is a good non-pharmacological option to treat depressive disorders (Josefsson et al., 2014; Stanton and Reaburn, 2014; Stubbs et al., in press; Wegner et al., 2014). It is also associated with better cardiorespiratory performance, physical fitness, metabolic syndrome in depressive patients (Kerling et al., 2015; Stubbs et al., 2016b). Studies show that exercise training reduces depressive symptoms in people with cardiovascular and neurological conditions (Adamson et al., 2015; Ensari et al., 2014; Tu et al., 2014). Furthermore, it has been suggested that physical activity increased hippocampal brain-derived neurotrophic factor (BDNF) levels and stimulates neurogenesis, similarly to anti-depressant medications. It can be a neurophysiologic mechanism that can explain the antidepressant properties of exercise (Carek et al., 2011; Lopresti et al., 2013).

Nevertheless, the effect of physical activity on bipolar disorder is unclear. Whereas bipolar disorder may be understood as an inflammatory disease (Drago et al., 2015; Leboyer et al., 2012), it is interesting to consider whether the anti-inflammatory properties of exercise are particularly important for bipolar disorder and could be a specific pathway to improve all its mood states (Kucyi et al., 2010). Conversely, physical activity increases body energy and has be associated with manic episodes (Sylvia et al., 2013a; Wright et al., 2012).

Prior reviews on this subject have only included a limited number of studies, and not research published in the last few years (Thomson et al., 2015; Vancampfort et al., 2013; Wright et al., 2009). Some reviews did not focus specifically on physical activity, but discuss exercise in context of other lifestyle interventions (Bauer et al., 2015; Kemp, 2014; Lopresti and Jacka, 2015; Nierenberg et al., 2015; Ward et al., 2015). Other reviews reported on the effects of exercise in mental illness as an umbrella diagnosis and did not analyze separately and thoroughly bipolar patients (Barbour et al., 2007; Kucyi et al., 2010; Stanton and Happell, 2014).

Considering the current evidence, the relationship between exercise and mood symptoms in bipolar patients needs to be further clarified. The objective of this study is to perform a systematic review in order to investigate the practice of physical exercise in bipolar patients and its influences in bipolar disorder.

\section{Methods}

\subsection{Search strategies}

Two researchers performed an electronic search of PubMed and Cochrane Library. The following keywords were used: 'physical activity' or 'sedentary' or 'physical exercise' and 'bipolar disorder' or 'mania' or 'bipolar depression'. Manual searches were also conducted, using reference lists from identified articles.

We included all articles published since 1995 Jan until 2016 Jan evaluating the relationship between bipolar disorder and physical exercise. Reviews, case reports, conference abstracts, and expert opinions were excluded. Articles that were duplicated or unavailable in English language were eliminated. Studies of patients with mental disorders without analysis according to diagnosis were removed.

\subsection{Data analysis}

The data was classified according to study design and participants. All articles were displayed on a table with the following data: names of authors, publication year, study design, physical activity assessment, main results and limitations, when available.

\section{Results}

\subsection{Study selection}

The initial electronic database search yielded 1671 hits. Five records were found from the reference list of identified studies. Initially, 1676 articles were included. After careful examination, 1542 were excluded: 115 were duplicated; 673 focused on other conditions; 182 referred to animal experiments and 572 were case reports, conference abstracts, and expert's opinions. Thereafter, 94 articles were removed: 8 were unavailable in English language; 1 was not located; 11 were reviews; 47 analyzed bipolar disorder and other mental diseases in the same group and 36 were evaluated physical health and not physical activity or exercise. Thirtyone studies were finally selected and included 15,587 patients with bipolar disorder in total (Fig. 1).

The results were organized considering the relevant topics: (1) physical activity levels in bipolar patients - 15 studies; (2) exercise and biomarkers - 3 studies; (3) comorbidities - 3 studies; (4) beneficial effects of exercise - 7 studies; (5) complications of exercise -4 studies (Table 1 ).

\subsection{Physical activity levels in bipolar patients}

Most studies showed that bipolar patients commonly had sedentary lifestyle, defined as absent or irregular practice of physical activity (Table 1). The majority of investigated psychiatric disorders (including bipolar disorder) were associated with lack of exercise (Chwastiak et al., 2011). The percentage of sedentary lifestyle in bipolar disorder varied from $40 \%$ to $64.9 \%$ in self-reported questionnaires (Cairney et al., 2009; Chwastiak et al., 2011; Gomes et al., 2013; Sylvia et al., 2013a).

Only one study assessed physical activity through objective measures. Motor activity levels of 60 bipolar patients were assessed using an actigraph. Most of them were classified as sedentary (around 78\%). Moreover, 21\% practiced light physical activity; and 1\%, moderate/vigorous (Janney et al., 2014).

Physical activity in children and adolescents was rarely studied. To the best of our knowledge, two studies focused on adolescents and none in children. Jewell et al. (2015) and Subramaniapillai 


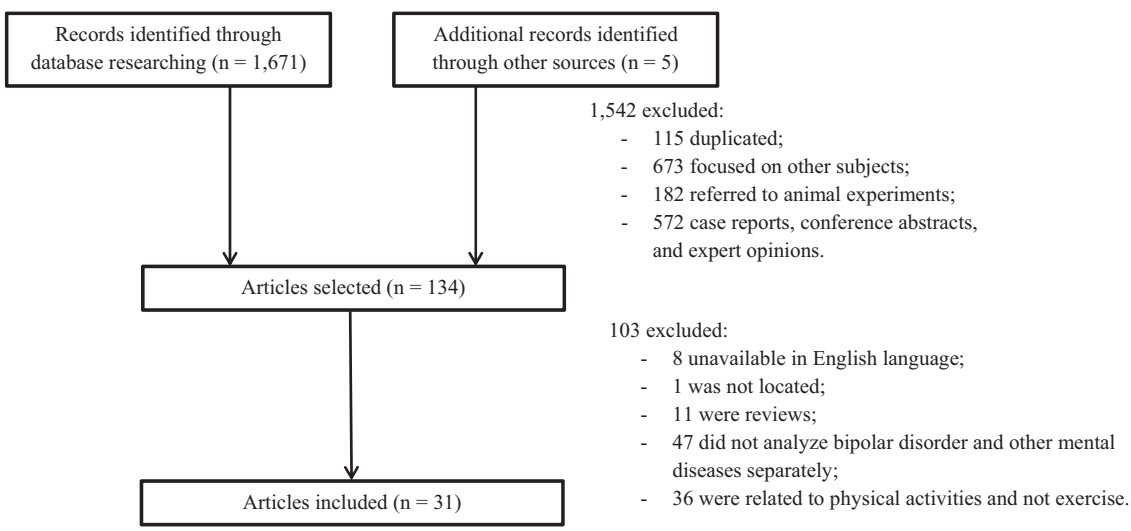

Fig. 1. Flowchart for study selection.

et al. (2016) compared adolescents with bipolar disorder and controls. In the first study, bipolar adolescents tended to practice less physical activities in general $(\mathrm{p}=0.10)$ and they reported less vigorous physical activity than controls $(\mathrm{p}=0.005)$ (Jewell et al., 2015). The second study showed that bipolar adolescents and controls experience a bout of exercise largely similar. Nevertheless, healthy adolescents reported a significantly greater tolerance for high intensity exercise than bipolar ones $(p<0.05)$ (Subramaniapillai et al., 2016).

Few studies evaluated motor and functional details of physical performance. Bipolar disorder was associated with poorer functional exercise capacity. They walked a shorter distance $(p<0.001)$, were less physically active $(p=0.005)$ and reported more musculoskeletal pain $(\mathrm{p}=0.03$ ) than controls (Vancampfort et al., 2015b). Patients had reduced speed of limb movement $(p<0.001)$, explosive leg strength $(p=0.003)$ and abdominal muscular endurance ( $\mathrm{p}<0.001$ ) (Vancampfort et al., 2015a). It was also observed that men had higher explosive muscle $(p=0.001)$ and handgrip strength $(\mathrm{p}<0.001)$ than women (Vancampfort et al., 2015a).

Most studies revealed that exercise duration and intensity were reduced in bipolar disorder when compared with controls (Elmslie et al., 2001; Hausdorff et al., 2004; Shah et al., 2007). Only one study found no difference in the total energy expenditure between the groups (Cairney et al., 2009).

Comparisons between bipolar disorder and major depressive disorder showed conflicting evidence. Cairney et al. (2009) demonstrated higher total energy expenditure in bipolar disorder than major depressive disorder $(\mathrm{p}=0.02)$; however there were no differences compared to control group $(p=0.39)$ (Cairney et al., 2009). Hausdorff et al. (2004) showed no differences in walking speed, swing time and stride time between depressive and bipolar patients (Hausdorff et al., 2004). However, compared to the control group, swing time variability was significantly larger in bipolar subjects $(\mathrm{p}<0.0001)$ and in subjects with major depression ( $p<0.0004)$. Chuang et al. (2008) concluded that the frequency of vigorous exercise did not differ between depression, bipolar and schizophrenia groups $(\mathrm{p}=0.16)$. There were also no differences in the frequency of getting as much exercise as is needed in three groups ( $\mathrm{p}=0.32$ ) (Chuang et al., 2008).

Two studies compared the physical activity in schizophrenia and bipolar patients. Bly et al. (2014) reported more physical activity in bipolar group $(\mathrm{p}=0.004)$ (Bly et al., 2014). On the other hand, Chuang et al. (2008) found no difference in frequency of vigorous exercise between these groups $(p=0.16)$ (Chuang et al., 2008).

\subsection{Exercise and biomarkers}

Alterations of biomarkers associated with physical exercise in bipolar patients were rarely investigated (Table 1). El-Mallakh et al. (2010) described an aberrant regulation of ouabain-like factor (OLF), an endogenous cardenolide, in bipolar subjects during exercises. In contrast, salivary cortisol levels were not different in two groups. Patients showed low rates of OLF before $(\mathrm{p}=0.019)$ during $(p=0.029)$ and after exercise $(p=0.020)$. Higher levels of OLF and an evident peak activity was found in controls. The physiologic actions of the endogenous cardenolides and the implications of this finding are still unknown (El-Mallakh et al., 2010).

Schuch et al. (2015) demonstrated higher brain-derived neurotrophic factor (BDNF) in bipolar patients before and after exercise testing. Only bipolar women had increased serum BDNF from pre- to post-test $(\mathrm{p}=0.004)$. No significant changes were observed in bipolar men or healthy people (men and women). These results indicate a gender related difference of exercise on BDNF levels in bipolar patients (Schuch et al., 2015).

Hays et al. (2008) assessed the effect of aerobic exercise on DHEAS levels (a precursor of the adrenal steroid dehydroepiandrosterone) and perceptions of well-being in bipolar patients. It was observed an improvement in perception of global well-being after exercise $(p<0.05)$. However, there was no correlation between DHEAS levels and perceptions of well-being $(p=0.38)$ (Hays et al., 2008).

\subsection{Comorbidities}

Studies have suggested an association between sedentary lifestyle and comorbidities in bipolar patients. Strohle et al. (2007) reported decreased prevalence of co-morbid mental disorder in patients who practices physical activity $(\mathrm{p}<0.05)$ (Strohle et al., 2007). Sedentary lifestyle was associated with sleep disturbance in bipolar patients $(\mathrm{p}<0.01)$, but not in controls (McGlinchey et al., 2014). The direction of the association is uncertain because these studies are cross-sectional.

Goodrich et al. (2010) assessed determinants of access to weight counseling in bipolar disorder. Atypical antipsychotics and increased BMI were associated with exercise counseling $(\mathrm{p}<0.05)$. Therefore, the study highlights the importance of advice on weight loss for bipolar patients, especially for those with increased cardiovascular risk (Goodrich et al., 2010).

\subsection{Beneficial effects of exercise}

Studies indicate that physical activity is associated with less depressive symptoms, better quality of life and increased functioning (Table 1). Sylvia et al. (2013a, 2013b) showed that less self- 
Table 1

Summary of selected studies.

\begin{tabular}{|c|c|c|c|c|}
\hline Author & Study design & Participants & Physical activity assessments or interventions & Results \\
\hline Elmslie et al., 2001 & Case-control & 89 euthymic BD and 445 controls & Life in New Zealand Questionnaire & $\begin{array}{l}\text { Patients had fewer episodes of low- to moderate-intensity and high-intensity } \\
\text { physical activity }\end{array}$ \\
\hline Hausdorff et al., 2004 & Case-control & $23 \mathrm{BD}, 19 \mathrm{MDD}$ and 9 control & Stride time and swing time during walking & $\begin{array}{l}\text { Patient groups tended to walk slowly, decreased swing time and increased stride } \\
\text { time }\end{array}$ \\
\hline Kilbourne et al., 2007 & Case-control & $2032 \mathrm{BD}, 1895 \mathrm{Sz}$ and 3065 control & Self-report & BD patients report poorer exercise habits - infrequent walking or strength exercises \\
\hline Ng et al., 2007 & $\begin{array}{l}\text { Retrospective cohort ( } 24 \\
\text { months) }\end{array}$ & $\begin{array}{l}49 \text { BD: } 14 \text { in a walking group and } 35 \\
\text { without physical activity }\end{array}$ & Walking program & $\begin{array}{l}\text { No differences in clinical global impression (CGI), but participants had lower scores } \\
\text { for depression anxiety stress scales (DASS) }\end{array}$ \\
\hline Shah et al., 2007 & Case-control & $14 \mathrm{BD}$ and 10 controls & $\begin{array}{l}\text { Time of exercise in treadmill with increase of } \\
\text { speed }\end{array}$ & $\begin{array}{l}\text { BD patients had reduced exercise duration. No difference in respiratory and } \\
\text { echocardiographic variables. }\end{array}$ \\
\hline Strohle et al., 2007 & $\begin{array}{l}\text { Community cohort ( } 4 \\
\text { years) }\end{array}$ & 2548 people (39 BD) & Self-report & $\begin{array}{l}\text { Increased physical activity was associated with high incidence of BD. Co-morbid } \\
\text { mental disorder associated with less exercise }\end{array}$ \\
\hline Chuang et al., 2008 & Cross-sectional & $\begin{array}{l}60 \mathrm{BD}, 61 \mathrm{Sz} \text {, and } 61 \mathrm{MDD} \text { or anxiety } \\
\text { disorders }\end{array}$ & Leisure-time physical activity questionnaire & $\begin{array}{l}24.2 \% \text { reported daily physical activity. Frequency of vigorous exercise did not differ } \\
\text { between groups. }\end{array}$ \\
\hline Hays et al., 2008 & Intervention & $26 \mathrm{BD}$ & Walking on a treadmill for $20 \mathrm{~min}$ & $\begin{array}{l}\text { Improvement in perception of global well-being after exercise. No association be- } \\
\text { tween Dehydroepiandrosterone Sulfate (DHEAS) levels and global well-being }\end{array}$ \\
\hline Salvi et al., 2008 & Cross-sectional & $108 \mathrm{BD}$ & Self-report & No relationship between exercise and metabolic syndrome \\
\hline Cairney et al., 2009 & Cross-sectional & $\begin{array}{l}831 \mathrm{BD} \text { vs } 4713 \mathrm{MDD} \text { vs } 31,834 \\
\text { control }\end{array}$ & Total energy expenditure (EE) & EE did not differ between $B D$ and control. EE was higher among BD than in MDD \\
\hline El-Mallakh et al., 2010 & Case-control & 14 euthymic BD and 10 controls & $\begin{array}{l}\text { Walking on a treadmill with progressively in- } \\
\text { creased speed }\end{array}$ & $\begin{array}{l}\text { Downregulation of a endogenous cardenolide before, during and after exercise in } \\
\text { BD patients }\end{array}$ \\
\hline Goodrich et al., 2010 & Cohort study (2 years) & 298 BD & Self-report & $\begin{array}{l}\text { Atypical antipsychotics and increased BMI were associated with exercise } \\
\text { counseling. }\end{array}$ \\
\hline Guan et al., 2010 & Cohort study (6 months) & $148 \mathrm{BD}$ and 65 control & Self-report & No relationship between exercise and metabolic syndrome \\
\hline Chwastiak et al., 2011 & Cross-sectional & 501,161 md (9522 BD) & Self-report & All psychiatric disorders (including BD) had lack of exercise as compared to control \\
\hline Salvi et al., 2011 & Cross-sectional & $200 \mathrm{BD}$ & Self-report & BD patients with metabolic syndrome had lower exercise levels \\
\hline Sylvia et al., 2011 & Intervention & $10 \mathrm{BD}$ & $\begin{array}{l}\text { Therapy with } 3 \text { modules: Nutrition, Exercise, and } \\
\text { Wellness }\end{array}$ & BD patients improved quality of life, depressive symptoms and weight \\
\hline Dakwar et al., 2012 & National cross-sectional & $23,505 \mathrm{md}(851 \mathrm{BD})$ & International Physical Activity Questionnaire & Vigorous exercise was associated with BD II and alcohol dependence \\
\hline Proudfoot et al., 2012 & Cross-sectional & $198 \mathrm{BD}$ & Self-report & Decreased physical exercise was associated with depressive episodes \\
\hline Wright et al., 2012 & Qualitative study & $25 \mathrm{BD}$ & Self-report & $\begin{array}{l}\text { Almost } 50 \% \text { used exercise to regulate symptoms. Exercise had different effects on } \\
\text { mood according to intensity }\end{array}$ \\
\hline Gomes et al., 2013 & Cross-sectional & $159 \mathrm{BD}$ & Self-report & High rates of physical inactivity (64.9\%) \\
\hline Sylvia et al., 2013a & Cross-sectional & 482 BD & Self-report & $\begin{array}{l}\text { Less exercise was associated with higher BMI, depressive symptoms, lower quality } \\
\text { of life and functioning. In contrast, more exercise was associated with mania }\end{array}$ \\
\hline Sylvia et al., 2013b & Intervention & $5 \mathrm{BD}$ & $\begin{array}{l}\text { Therapy with } 3 \text { modules: Nutrition, Exercise, and } \\
\text { Wellness }\end{array}$ & $\begin{array}{l}\text { Less physical activity was associated with more depressive symptoms, lower } \\
\text { quality of life and functioning. }\end{array}$ \\
\hline Bly et al., 2014 & Cross-sectional & $116 \mathrm{BD}$ and $143 \mathrm{Sz}$ & Total Activity Measure 2 (TAM2) & BD patients reported more physical activity than Sz. \\
\hline Janney et al., 2014 & Cross-sectional & $60 \mathrm{BD}$ & Actigraphy & $\begin{array}{l}\text { BD patients were more inactive ( } 78 \% \text { ). } 21 \% \text { practiced light physical activity; and } 1.4 \% \\
\text { moderate/vigorous }\end{array}$ \\
\hline McGlinchey et al., 2014 & Case-control & 32 euthymic BD and 36 controls & Self-report and actigraphy & $\begin{array}{l}\text { BD patients tended to have reduced physical activity. It was a predictor of sleep } \\
\text { disorder in BD, but not in controls }\end{array}$ \\
\hline Jewell et al., 2015 & Case-control & $86 \mathrm{BD}$ adolescents and 50 controls & $\begin{array}{l}\text { 17-item Quick Weight, Activity \& Excess Screener } \\
\text { (WAVE) }\end{array}$ & $\begin{array}{l}\text { Physical activity tends to be lower in BD. Patients with low physical activity were } \\
\text { less likely to have a family history of substance use }(\mathrm{p}=0.03)\end{array}$ \\
\hline Schuch et al., 2015 & Case-control & $18 \mathrm{BD}$ and 18 controls & Measurement of BDNF before and after exercise & BD patients had higher BDNF levels, both at pre-and post-test \\
\hline Vancampfort et al., 2015a & Cross-sectional & $46 \mathrm{BD}$ & EUROFIT test battery & Men had higher explosive muscle and handgrip strength than women. \\
\hline Vancampfort et al., 2015a & Case-control & $30 \mathrm{BD}$ and 30 controls & $\begin{array}{l}\text { EUROFIT test and International Physical Activity } \\
\text { Questionnaire }\end{array}$ & $\begin{array}{l}\text { BD patients had reduced speed of limb movement, explosive leg strength and ab- } \\
\text { dominal muscular endurance }\end{array}$ \\
\hline Vancampfort et al., 2015b & Case-control & $30 \mathrm{BD}$ and 30 controls & $\begin{array}{l}\text { International Physical Activity Questionnaire and } \\
6 \text { min walk test }\end{array}$ & BD patients had poorer functional exercise capacity \\
\hline Subramaniapillai et al., 2016 & Case-control & $32 \mathrm{BD}$ adolescents and 31 controls & Exercise-Induced Feeling Inventory (EFI) & $\begin{array}{l}\text { There were no differences between groups on any subscales. Controls reported } \\
\text { greater tolerance for high intensity exercise than BD. }\end{array}$ \\
\hline
\end{tabular}

BD: Bipolar disorder

md: mental disorders

MDD: Major depressive disorder

Sz: Schizophrenia

$\mathrm{EE}$ : energy expenditure 
reported exercise was associated with higher depressive symptoms $(\mathrm{p}<0.001)$, and lower quality of life $(\mathrm{p}=0.032)$ and functioning ( $\mathrm{p}<0.001$ ) (Sylvia et al., 2013a). Proudfoot et al. (2012) also identified a relationship between decreased physical exercise and depressive episodes ( $p<0.001$ ) (Proudfoot et al., 2012).

In a qualitative study, 25 bipolar patients answered a semistructured interview about their views on the relationship between exercise and bipolar disorder. Almost 50\% used exercise to regulate symptoms (Wright et al., 2009).

Some intervention studies support effects of exercise on mood. $\mathrm{Ng}$ et al. (2007) invited bipolar inpatients to participate voluntarily in a walking group during admissions. The walking group had lower scores in Depression Anxiety Stress Scales - DASS $(\mathrm{p}=0.005)$ and all its subscales (Depression $\mathrm{p}=0.048$, Anxiety $p=0.002$, Stress $p=0.01$ ). Nevertheless, there was no difference in Clinical Global Impression (CGI) between two groups ( $p>0.05$ ) (Ng et al., 2007). Sylvia et al. (2011,2013b) assessed the effects of nutrition/weight loss, exercise, and wellness treatment. These studies involved a combined of three treatment modules, administered in twelve 60-min group sessions over 14 weeks. The treatment tends to improve quality of life, depressive symptoms, functioning and weight (Sylvia et al., 2011, 2013b).

Most studies revealed a high prevalence of metabolic syndrome in bipolar patients. Nonetheless, the relationship between metabolic syndrome and physical activity in this population is uncertain. Guan et al. (2010) and Salvi et al. (2008) showed higher rates of hyperglycemia, dyslipidemia, hypertension and metabolic syndrome in bipolar patients. However, a relationship between metabolic syndrome and physical activity was not found (Guan et al., 2010 p=0.986; Salvi et al., 2008 p=0.232). Salvi et al. (2011), in a larger sample, demonstrated that bipolar with the metabolic syndrome practiced less exercise $(\mathrm{p}=0.030)$ (Salvi et al., 2011).

\subsection{Complications of exercise}

Two studies estimates higher incidence of bipolar disorder in people that practices more physical activities. Strohle et al. (2007) followed 2548 people over four years in a community, including 959 with mental disorders and 39 with bipolar. At baseline, any mental disorder was associated with irregular physical activity (OR 0.69; CI 0.56-0.84, $\mathrm{p}<0.05$ ), but not in bipolar patients (OR 1.23, CI $0.58-2.60, \mathrm{p}>0.05$ ). Over 4 years, the incidence of mental disorders in general was higher in people with irregular exercise or no exercise (OR $0.71, \mathrm{Cl} 0.53-0.95, \mathrm{p}>0.05$ ). In contrast, those who practices regularly physical activity were associated with bipolar disorder (OR 10.29, CI 1.36-78.08, p < 0.05) (Strohle et al., 2007). In a national survey with 23,505 people with mental disorders (851 with bipolar disorder), vigorous exercise was associated with a vulnerability to some mental illness, especially alcohol dependence (OR 1.43, CI 1.12-1.84, p < 0.05) and bipolar II disorder (OR 2.29, CI 1.31-4.02, p < 0.05) (Dakwar et al., 2012).

Interestingly, some studies associated physical activity with manic episodes. Sylvia et al., 2013a showed that less exercise was associated with depressive symptoms $(\mathrm{p}<0.001)$, and frequent exercise with mania ( $\mathrm{p}=0.012$ ) (Sylvia et al., 2013a). However, this study is cross-sectional, which limits its conclusions. The findings possibly can be explained because individuals who are manic tend to exercise more. In a qualitative study, Wright et al. (2009) suggested that physical activity has different effects on bipolar patients, depending upon the severity of the exerciser's mood state (Wright et al., 2009). It could relieve symptoms of hypomania and prevent severe mood swings. However, vigorous exercise may worsen mania or hypomania.

\section{Discussion}

This review shows that evidence about the effects of physical activity on bipolar disorder is scarce. The majority of studies are cross-sectional evaluations of patients compared, or not, to controls. Only three prospective cohorts were reported in this review. However, neither of them evaluated the effects of physical activity on symptoms, quality of life and functioning. Two intervention studies evaluated the effects of a combined therapy including nutrition, physical activity and lifestyle. They showed benefit in quality of life, depressive symptoms and functioning. However, none assessed the exercise as a single intervention strategy. No prospective randomized controlled trial was identified.

Current evidence shows that bipolar patients lead a sedentary life, which has been associated with more comorbidities, poorer quality of life, worse functioning and more depressive symptoms in bipolar disorder. These findings are in accordance with studies in populations with mental disorders (Carneiro et al., 2016; Ho et al., 2016), indicating worse evolution of sedentary patients. However, studies in children and adolescents are scarce and needy.

The pathways by which exercise acts in bipolar disorder are unclear. The effects of exercise on BDNF levels in bipolar were poorly studied, despite its strong influence on brain functions. Aerobic exercise raises BDNF levels, associated with the chronic stress suppression, frequently found in bipolar patients (Heijnen et al., 2016; De Sá Filho et al., 2015). Some animal experiments showed that exercise independently attenuate mania-like behavior (Kirshenbaum et al., 2014). Besides, exercise contributes to reduce oxidative stress and inflammatory activity (Muneer, 2016; Sallam and Laher, 2016). Available evidence supports the important role of inflammation on bipolar disorder (Goldstein et al., 2009). Studies with BDNF and inflammatory cytokines in bipolar patients are much needed.

The impact of physical activity on sleep has been little studied in bipolar patients. There is a complex and bilateral interaction between exercise and sleep (Chennaoui et al., 2015). Poor sleep quality has been associated with residual mood symptoms, mood episode recurrence in bipolar patients and poor work performance (Boland et al., 2015; Cretu et al., 2016). It is necessary to study the influence of physical activity on sleep in bipolar patients.

Studies about the effects of physical activity on the metabolic syndrome in bipolar patients showed uncertain results. Similarly to other physical and mental conditions (Kahl et al., 2015; Liu et al., 2015; Park and Larson, 2014), physical activity should improve anthropometric measures and impact positively on metabolic syndrome. Possibly, an explanation for the few available studies may be the difficulty in recruiting and the adherence to physical exercise in bipolar population with frequent severe behavioral symptoms. In summary, the relationship between physical exercise and metabolic syndrome also needs further clarification.

Despite the highlighted beneficial effects of exercise, some studies suggest that frequent exercise is associated with mania in bipolar patients. It is unknown if the exacerbation of manic symptoms is cause or consequence of increased physical activity. It is also unclear if the manic state is associated with only vigorous exercise or with any kind of physical activity. Therefore, cohorts are needed to clarify this important subject.

Although there are previous reviews about the topic (Thomson et al., 2015; Vancampfort et al., 2013; Wright et al., 2009), this systematic review includes a larger number of articles. Eight recent publications (including 390 patients) are new to this review compared three prior ones. Furthermore, many gaps remain and it implies that the subject should be studied constantly.

Several limitations should be acknowledged. The small number of studies about same topic, the diversity in physical activity measures, the different types of study design and the 
heterogeneous samples prevented us from performing meta-analysis. Most studies were cross-sectional, which limits establishing a cause and effect relationship. Furthermore, the motivation for exercising can be a selection bias in majority of cases. Some intervention simultaneously promoted nutrition, lifestyle changes and physical activity, hampering to infer conclusions about the only physical exercise. Other limitation was the lack of studies comparing exercise across mood states and assessing effects of medications on exercise.

In conclusion, sedentary lifestyle is common in bipolar patients. Physical exercise was associated with better functioning, quality of life and depressive symptoms. Some studies report the relationship between vigorous exercise and mania. However, evidence was insufficient to infer a cause-effect relationship and randomized trials are suggested. Other issues to be considered are the influence of exercise on sleep and its neurochemical changes on bipolar disorder.

\section{Role of the funding source}

The authors do not have a financial relation with a commercial entity that has an interest in the content of this paper.

\section{Declaration of interest}

The authors report no conflicts of interest. The authors are responsible for the content and writing of the paper.

\section{Contributors}

MCAM conceived and designed the study, collected data and analyzed data. EDFD, SGCA and VMSB contributed to the conception and design of the study. All authors contributed to the drafting, and revisions of the manuscript. All authors read and approved the final manuscript.

\section{References}

Adamson, B.C., Ensari, I., Motl, R.W., 2015. Effect of exercise on depressive symptoms in adults with neurologic disorders: a systematic review and meta-analysis. Arch. Phys. Med. Rehabil. 96, 1329-1338.

Anderson, I.M., Haddad, P.M., Scott, J., 2012. Bipolar disorder. BMJ 345, e8508.

Bauer, I.E., Gálvez, J.F., Hamilton, J.E., Balanzá-Martínez, V., Zunta-Soares, G.B. Soares, J.C., Meyer, T.D., 2015. Lifestyle interventions targeting dietary habits and exercise in bipolar disorder: a systematic review. J. Psychiatr. Res. 74, 1-7.

Bly, M.J., Taylor, S.F., Dalack, G., Pop-Busui, R., Burghardt, K.J., Evans, S.J., McInnis, M. I., Grove, T.B., Brook, R.D., Zollner, S.K., Ellingrod, V.L., 2014. Metabolic syndrome in bipolar disorder and schizophrenia: dietary and lifestyle factors compared to the general population. Bipolar Disord. 16, 277-288.

Barbour, K.A., Edenfield, T.M., Blumenthal, J.A., 2007. Exercise as a treatment for depression and other psychiatric disorders: a review. J. Cardiopulm. Rehabil. Prev. 27, 359-367.

Boland, E.M., Stange, J.P., Molz Adams, A., LaBelle, D.R., Ong, M.L., Hamilton, J.L., Connolly, S.L., Black, C.L., Cedeño, A.B., Alloy, L.B., 2015. Associations between sleep disturbance, cognitive functioning and work disability in bipolar disorder. Psychiatry Res. 230, 567-574.

Cairney, J., Veldhuizen, S., Faulkner, G., Schaffer, A., Rodriguez, M.C., 2009. Bipolar disorder and leisure-time physical activity: results from a national survey of Canadians. Ment. Health Phys. Act. 2, 65-70.

Carek, P.J., Laibstain, S.E., Carek, S.M., 2011. Exercise for the treatment of depression and anxiety. Int. J. Psychiatry Med. 41, 15-28.

Carneiro, L.S., Fonseca, A.M., Serrão, P., Mota, M.P., Vasconcelos-Raposo, J., VieiraCoelho, M.A., 2016. Impact of physical exercise on catechol-O-methyltransferase activity in depressive patients: a preliminary communication. J. Affect. Disord. 193, 117-122.

Chennaoui, M., Arnal, P.J., Sauvet, F., Leger, D., 2015. Sleep and exercise: a reciproca issue? Sleep. Med. Rev. 20, 59-72.

Chuang, H.T., Mansell, C., Patten, S.B., 2008. Lifestyle characteristics of psychiatric outpatients. Can. J. Psychiatry 53, 260-266.
Chwastiak, L.A., Rosenheck, R.A., Kazis, L.E., 2011. Association of psychiatric illness and obesity, physical inactivity, and smoking among a national sample of veterans. Psychosomatics 52, 230-236.

Cretu, J.B., Culver, J.L., Goffin, K.C., Shah, S., Ketter, T.A., 2016. Sleep, residual mood symptoms, and time to relapse in recovered patients with bipolar disorder. J. Affect. Disord. 190, 162-166.

Dakwar, E., Blanco, C., Lin, K.H., Liu, S.M., Warden, D., Trivedi, M., Nunes, E.V., 2012. Exercise and mental illness: results from the National Epidemiologic Survey on Alcohol and Related Conditions (NESARC). J. Clin. Psychiatry 73, 960-966.

De Sa Filho, A.S., Moura, A.M.S., Lamego, M.K., Rocha, N.B.F., Paes, F., Oliveira, A.C., Lattari, E., Rimes, R., Manochio, J., Budde, H., Wegner, M., Mura, G., Arias-Carrión, O., Cheniaux, E., Yuan, T.F., Nardi, A.E., Machado, S., 2015. Potential therapeutic effects of physical exercise for bipolar disorder. CNS Neurol. Disord. Drug. Targets 14, 1255-1259.

Drago, A., Crisafulli, C., Calabrò, M., Serretti, A., 2015. Enrichment pathway analysis. the inflammatory genetic background in bipolar disorder. J. Affect. Disord. 179, 88-94.

El-Mallakh, R.S., Stoddard, M., Jortani, S.A., El-Masri, M.A., Sephton, S., Valdes Jr., R., 2010. Aberrant regulation of endogenous ouabain-like factor in bipolar subjects. Psychiatry Res. 178, 116-120.

Elmslie, J.L., Mann, J.I., Silverstone, J.T., Williams, S.M., Romans, S.E., 2001. Determinants of overweight and obesity in patients with bipolar disorder. J. Clin, Psychiatry 62, 486-491, Ouiz 492-483.

Ensari, I., Motl, R.W., Pilutti, L.A., 2014. Exercise training improves depressive symptoms in people with multiple sclerosis: results of a meta-analysis. J. Psychosom. Res. 76, 465-471.

Geddes, J.R., Miklowitz, D.J., 2013. Treatment of bipolar disorder. Lancet 381, 1672-1682.

Gomes, F.A., Almeida, K.M., Magalhaes, P.V., Caetano, S.C., Kauer-Sant'Anna, M., Lafer, B., Kapczinski, F., 2013. Cardiovascular risk factors in outpatients with bipolar disorder: a report from the Brazilian Research Network in Bipolar Disorder. Rev. Bras. Psiquiatr. 35, 126-130.

Goodrich, D.E., Lai, Z., Lasky, E., Burghardt, A.R., Kilbourne, A.M., 2010. Access to weight loss counseling services among patients with bipolar disorder. J. Affect. Disord. 126, 75-79.

Guan, N., Liu, H., Diao, F., Zhang, J., Zhang, M., Wu, T., 2010. Prevalence of metabolic syndrome in bipolar patients initiating acute-phase treatment: a 6-month follow up. Psychiatry Clin. Neurosci. 64, 625-633.

Hausdorff, J.M., Peng, C.K., Goldberger, A.L., Stoll, A.L., 2004. Gait unsteadiness and fall risk in two affective disorders: a preliminary study. BMC. Psychiatry 4, 39.

Hays, A.E., Goss, F., Aaron, D., Abt, K., Friedman, E., Gallagher, M., Nagle, E., 2008. Hormonal and perceptual changes in bipolar subjects after acute aerobic exercise. Med. Sci. Sports Exerc. 40, S17.

Heijnen, S., Hommel, B., Kibele, A., Colzato, L.S., 2016. Neuromodulation of aerobic exercise - a review. Front. Psychol. 6, 1890.

Ho, R.T., Fong, T.C., Wan, A.H., Au-Yeung, F.S., Wong, C.P., Ng, W.Y., Cheung, I.K., Lo, P. H., Ng, S.M., Chan, C.L., Chen, E.Y., 2016. A randomized controlled trial on the psychophysiological effects of physical exercise and Tai-chi in patients with chronic schizophrenia. Schizophr. Res. 171, 42-49.

Janney, C.A., Fagiolini, A., Swartz, H.A., Jakicic, J.M., Holleman, R.G., Richardson, C.R., 2014. Are adults with bipolar disorder active? Objectively measured physical activity and sedentary behavior using accelerometry. J. Affect. Disord. 152-154, 498-504.

Josefsson, T. Lindwall, M., Archer, T, 2014. Physical exercise intervention in depressive disorders: meta-analysis and systematic review. Scand. J. Med. Sci. Sports 24, 259-272.

Jewell, L., Abtan, R., Scavone, A., Timmins, V., Swampillai, B., Goldstein, B.I., 2015. Preliminary evidence of disparities in physical activity among adolescents with bipolar disorder. Ment. Health Phys. Act. 8, 62-67.

Kahl, K.G., Schweiger, U., Correll, C., Muller, C., Busch, M.L., Bauer, M., Schwarz, P., 2015. Depression, anxiety disorders, and metabolic syndrome in a population at risk for type 2. Diabetes Mellit. Brain Behav. 5, e00306.

Kemp, D.E., 2014. Managing the side effects associated with commonly used treatments for bipolar depression. J. Affect. Disord. 169 (Suppl. 1), S34-S44.

Kendall, T., Morriss, R., Mayo-Wilson, E., Marcus, E., Guideline Development Group of the National Institute for, H., Care, E., 2014. Assessment and management of bipolar disorder: summary of updated NICE guidance. BMJ 349, g5673.

Kerling, A., Tegtbur, U., Gützlaff, E., Kück, M., Borchert, L., Ates, Z., von Bohlen, A. Frieling, H., Hüper, K., Hartung, D., Schweiger, U., Kahl, K.G., 2015. Effects of adjunctive exercise on physiological and psychological parameters in depression: a randomized pilot trial. J. Affect. Disord. 177, 1-6.

Kilbourne, A.M., Rofey, D.L., McCarthy, J.F., Post, E.P., Welsh, D., Blow, F.C., 2007. Nutrition and exercise behavior among patients with bipolar disorder. Bipolar disorders 9, 443-452.

Kirshenbaum, G.S., Burgess, C.R., Dery, N., Fahnestock, M., Peever, J.H., Roder, J.C. 2014. Attenuation of mania-like behavior in $\mathrm{Na}(+), \mathrm{K}(+)$-ATPase alpha3 mutant mice by prospective therapies for bipolar disorder: melatonin and exercise. Neuroscience 260, 195-204.

Kucyi, A., Alsuwaidan, M.T., Liauw, S.S., McIntyre, R.S., 2010. Aerobic physical exercise as a possible treatment for neurocognitive dysfunction in bipolar disorder. Postgrad. Med. J. 122, 107-116.

Leboyer, M., Soreca, I., Scott, J., Frye, M., Henry, C., Tamouza, R., Kupfer, D.J., 2012. Can bipolar disorder be viewed as a multi-system inflammatory disease? J. Affect. Disord. 141, 1-10.

Liu, S.H., Waring, M.E., Eaton, C.B., Lapane, K.L., 2015. Association of objectively measured physical activity and metabolic syndrome among us adults with 
osteoarthritis. Arthritis Care Res. 67, 1371-1378.

Lopresti, A.L., Jacka, F.N., 2015. Diet and bipolar disorder: a review of its relationship and potential therapeutic mechanisms of action. J. Altern. Complement. Med. 21, 733-739.

Lopresti, A.L., Hood, S.D., Drummond, P.D., 2013. A review of lifestyle factors that contribute to important pathways associated with major depression: diet, sleep and exercise. J. Affect. Disord. 148, 12-27.

McCormick, U., Murray, B., McNew, B., 2015. Diagnosis and treatment of patients with bipolar disorder: a review for advanced practice nurses. J. Am. Assoc. Nurse Pract. 27, 530-542.

McGlinchey, E.L., Gershon, A., Eidelman, P., Kaplan, K.A., Harvey, A.G., 2014. Physical activity and sleep: day-to-day associations among individuals with and without bipolar disorder. Ment. Health Phys. Act. 7, 183-190.

Morriss, R., Mohammed, F.A., 2005. Metabolism, lifestyle and bipolar affective disorder. J. Psychopharmacol. 19, 94-101.

Moylan, S., Eyre, H.A., Maes, M., Baune, B.T., Jacka, F.N., Berk, M., 2013. Exercising the worry away: how inflammation, oxidative and nitrogen stress mediates the beneficial effect of physical activity on anxiety disorder symptoms and behaviours. Neurosci. Biobehav. Rev. 37, 573-584.

Muneer, A., 2016. Bipolar disorder: role of inflammation and the development of disease biomarkers. Psychiatry Invest. 13, 18-33.

Nierenberg, A.A., Hearing, C.M., Sande Mathias, I., Young, L.T., Sylvia, L.G., 2015 Getting to wellness: the potential of the athletic model of marginal gains for the treatment of bipolar disorder. Aust. N. Z. J. Psychiatry 49, 1207-1214.

$\mathrm{Ng}, \mathrm{F}$., Dodd, S., Berk, M., 2007. The effects of physical activity in the acute treatment of bipolar disorder: a pilot study. J. Affect. Disord. 101, 259-262.

Park, S.K., Larson, J.L., 2014. The relationship between physical activity and metabolic syndrome in people with chronic obstructive pulmonary disease. J. Cardiovasc. Nurs. 29, 499-507.

Petersen, A.M., Pedersen, B.K., 2005. The anti-inflammatory effect of exercise. J. Appl. Physiol. 98, 1154-1162.

Price, A.L., Marzani-Nissen, G.R., 2012. Bipolar disorders: a review. Am. Fam. Phys. 85, 483-493.

Proudfoot, J., Whitton, A., Parker, G., Doran, J., Manicavasagar, V., Delmas, K., 2012. Triggers of mania and depression in young adults with bipolar disorder. J. Affect. Disord. 143, 196-202.

Sallam, N., Laher, I., 2016. Exercise modulates oxidative stress and inflammation in aging and cardiovascular diseases. Oxid. Med. Cell. Longev. 〈http://www.hinda wi.com/journals/omcl/2016/7239639/> (accessed 31.1.16

Salvi, V., Albert, U., Chiarle, A., Soreca, I., Bogetto, F., Maina, G., 2008. Metabolic syndrome in Italian patients with bipolar disorder. Gen. Hosp. Psychiatry 30, 318-323.

Salvi, V., D'Ambrosio, V., Rosso, G., Bogetto, F., Maina, G., 2011. Age-specific prevalence of metabolic syndrome in Italian patients with bipolar disorder. Psychiatry Clin. Neurosci. 65, 47-54.

Schuch, F.B., da Silveira, L.E., de Zeni, T.C., da Silva, D.P., Wollenhaupt-Aguiar, B., Ferrari, P., Reischak-Oliveira, A., Kapczinski, F., 2015. Effects of a single bout of maximal aerobic exercise on BDNF in bipolar disorder: a gender-based response. Psychiatry Res. 229, 57-62.

Shah, A., Alshaher, M., Dawn, B., Siddiqui, T., Longaker, R.A., Stoddard, M.F., ElMallakh, R., 2007. Exercise tolerance is reduced in bipolar illness. J. Affect. Disord. 104, 191-195.

Stanton, R., Happell, B., 2014. Exercise for mental illness: a systematic review of inpatient studies. Int. J. Ment. Health Nurs. 23, 232-242.

Stanton, R., Reaburn, P., 2014. Exercise and the treatment of depression: a review of the exercise program variables. J. Sci. Med. Sport. 17, 177-182.

Strohle, A., Hofler, M., Pfister, H., Muller, A.G., Hoyer, J., Wittchen, H.U., Lieb, R., 2007. Physical activity and prevalence and incidence of mental disorders in adolescents and young adults. Psychol. Med. 37, 1657-1666.

Subramaniapillai, M., Goldstein, B.I., MacIntosh, B.J., Korczak, D.J., Ou, X., Scavone,
A., Arbour-Nicitopoulos, K., Faulkner, G., 2016. Characterizing exercise-induced feelings after one bout of exercise among adolescents with and without bipolar disorder. J. Affect. Disord. 190, 467-473.

Sylvia, L.G., Friedman, E.S., Kocsis, J.H., Bernstein, E.E., Brody, B.D., Kinrys, G., Kemp D.E., Shelton, R.C., McElroy, S.L., Bobo, W.V., Kamali, M., McInnis, M.G., Tohen, M., Bowden, C.L., Ketter, T.A., Deckersbach, T., Calabrese, J.R., Thase, M.E., ReillyHarrington, N.A., Singh, V., Rabideau, D.J., Nierenberg, A.A., 2013a. Association of exercise with quality of life and mood symptoms in a comparative effectiveness study of bipolar disorder. J. Affect. Disord. 151, 722-727.

Sylvia, L.G., Nierenberg, A.A., Stange, J.P., Peckham, A.D., Deckersbach, T., 2011 Development of an integrated psychosocial treatment to address the medical burden associated with bipolar disorder. J. Psychiatr. Pract. 17, 224-232.

Sylvia, L.G., Salcedo, S., Bernstein, E.E., Baek, J.H., Nierenberg, A.A., Deckersbach, T., 2013b. Nutrition, exercise, and wellness treatment in bipolar disorder: proof of concept for a consolidated intervention. Int. J. Bipolar Disord. 1, 24.

Stubbs, B., Vancampfort, D., Rosenbaum, S., Ward, P.B., Richards, J., Ussher, M., Schuch, F.B., 2016a. Challenges establishing the efficacy of exercise as an antidepressant treatment: a systematic review and meta-analysis of control group responses in exercise randomised controlled trials. Sports Med., In press

Stubbs, B., Rosenbaum, S., Vancampfort, D., Ward, P.B., Schuch, F.B., 2016b. Exercise improves cardiorespiratory fitness in people with depression: a meta-analysis of randomized control trials. J. Affect. Disord. 190, 249-253.

Ten Have, M., de Graaf, R., Monshouwer, K., 2011. Physical exercise in adults and mental health status findings from the Netherlands mental health survey and incidence study (NEMESIS). J. Psychosom. Res. 71, 342-348.

Thomson, D., Turner, A., Lauder, S., Gigler, M.E., Berk, L., Singh, A.B., Pasco, J.A., Berk M., Sylvia, L., 2015. A brief review of exercise, bipolar disorder, and mechanistic pathways. Front Psychol. 6, 147.

Tu, R.H., Zeng, Z.Y., Zhong, G.Q., Wu, W.F., Lu, Y.J., Bo, Z.D., He, Y., Huang, W.Q., Yao, L M., 2014. Effects of exercise training on depression in patients with heart failure: a systematic review and meta-analysis of randomized controlled trials. Eur. J. Heart Fail. 16, 749-757.

Vancampfort, D., Correll, C.U., Probst, M., Sienaert, P., Wyckaert, S., De Herdt, A., Knapen, J., De Wachter, D., De Hert, M., 2013. A review of physical activity correlates in patients with bipolar disorder. J. Affect. Disord. 145, 285-291.

Vancampfort, D., Sienaert, P., Wyckaert, S., De Hert, M., Stubbs, B., Rosenbaum, S., Buys, R., Probst, M., 2015a. Test-retest reliability, feasibility and clinical correlates of the Eurofit test battery in people with bipolar disorder. Psychiatry Res. 228, 620-625.

Vancampfort, D., Sienaert, P., Wyckaert, S., De Hert, M., Stubbs, B., Soundy, A., De Smet, J., Probst, M., 2015a. Health-related physical fitness in patients with bipolar disorder vs. healthy controls: an exploratory study. J. Affect. Disord. 177 22-27.

Vancampfort, D., Wyckaert, S., Sienaert, P., De Hert, M., Stubbs, B., Buys, R., Schueremans, A., Probst, M., 2015b. The functional exercise capacity in patients with bipolar disorder versus healthy controls: a pilot study. Psychiatry Res. 229, 194-199.

Ward, M.C., White, D.T., Druss, B.G., 2015. A meta-review of lifestyle interventions for cardiovascular risk factors in the general medical population: lessons for individuals with serious mental illness. J. Clin. Psychiatry 76, 477-486.

Wegner, M., Helmich, I., Machado, S., Nardi, A.E., Arias-Carrion, O., Budde, H., 2014 Effects of exercise on anxiety and depression disorders: review of meta-analyses and neurobiological mechanisms. CNS Neurol. Disord. Drug. Targets 13, 1002-1014.

Wright, K., Armstrong, T., Taylor, A., Dean, S., 2012. 'It's a double edged sword': a qualitative analysis of the experiences of exercise amongst people with bipolar disorder. J. Affect. Disord. 136, 634-642.

Wright, K.A., Everson-Hock, E.S., Taylor, A.H., 2009. The effects of physical activity on physical and mental health among individuals with bipolar disorder: a systematic review. Ment. Health Phys. Act. 2, 86-94. 